\title{
Effects Of Adenosine On Apoptosis Of Ovarian Cancer A2780 Cells Via ROS And Caspase Pathways
}

This article was published in the following Dove Press journal: OncoTargets and Therapy

\section{Bing Xia \\ Jing Wang}

Hunan Cancer Hospital and the Affiliated Tumor Hospital of Xiang-Ya School of Medicine, Central South University, Changsha 410078, People's Republic of China
Correspondence: Jing Wang Hunan Cancer Hospital, the Affiliated Tumor Hospital of Xiang-Ya School of Medicine, Central South University, Changsha 410078, People's Republic of China

Tel +86I354865I 043

Email wangjing_hnzyyy@I63.com
Background: Ovarian cancer is the second most common malignant tumor of the female genital tract and the main cause of death of gynecological malignant tumors. Exogenous adenosine has been shown to induce apoptosis in tumor cells.

Materials and methods: The current study aimed to investigate the inhibitory effect and underlying mechanism of adenosine on the proliferation of ovarian cancer cells. The inhibitory effects of adenosine on ovarian cancer cells were assessed through MTT assay. The adenosine-induced apoptosis was determined by Hoechst 33342 staining and flow cytometry. The effect of adenosine on the intracellular reactive oxygen species (ROS) and mitochondrial membrane potential (MMP) was assessed according to the DCFH-DA and JC1 methods, respectively. Expression of apoptosis-related proteins and mitochondrial proteins was measured using Western blotting.

Results: MTT suggested that adenosine inhibited A2780 and SKOV3 cells viability in a dose- and time-dependent manner $(P<0.05)$. Hoechst 33342 staining had demonstrated pronounced changes in cell morphology; to be specific, cells treated with $0 \mathrm{mmol} / \mathrm{L}$ adenosine showed a light blue color, while those in treatment groups had nuclear pyknosis and apoptotic body formation. Besides, the apoptosis rate was positively correlated with adenosine concentration $(P<0.05)$. Flow cytometry results revealed that adenosine increased the intracellular ROS level and decreased MMP. Western blotting indicated that, the expression of Bax, cleaved-caspase-3 and cleaved-poly (ADP-ribose) polymerase was up-regulated with the increase in adenosine concentration, while that of Bcl-2 protein and apoptosis-related protein caspase-3 was down-regulated.

Conclusion: With the increase in drug concentration, the CytoC expression in mitochondria was gradually reduced, while that in the cytoplasm was gradually increased. In conclusion, Ado may inhibit the proliferation and induce the apoptosis of ovarian cancer cells by increasing ROS, up-regulating the pro-apoptotic protein Bax and activating the caspase-3 expression in vitro.

Keywords: adenosine, apoptosis, ROS, caspase pathway, ovarian cancer

Ovarian cancer, one of the three leading malignant tumors in the female reproductive system, ranks the top in all malignant gynecological tumors in terms of its mortality rate. ${ }^{1}$ The incidence of ovarian cancer is increasing gradually in recent years. However, ovarian cancer has hidden early symptoms, and patients have already developed distant metastases (DM) before the emergence of noticeable symptoms. On this account, over $70 \%$ of patients are in the advanced stage at the time of diagnosis. $^{2}$ Surgery and chemotherapy can alleviate the symptoms; however, they 
can not radically eliminate the problem, and most advanced patients suffer a relapse within 2-3 years, eventually leading to death as a result of chemotherapeutic resistance. ${ }^{3,4}$ The cytotoxicity of nucleosides has become a research hotspot over the past few years, and the antitumor effects of adenosine are even more encouraging. ${ }^{5}$ Nonetheless, the action of adenosine may differ depending on the different cell lines. For instance, in some cell lines, they are mediated by the receptor pathway, ${ }^{6}$ while in others, they remain active after entering the cells. ${ }^{7}$

Mitochondria play critical roles in calcium homeostasis, intermediary metabolism, and energy production. Besides, they are the vital apoptosis sensors. ${ }^{89}$ Mitochondria account for the main ROS production sites, while the excess ROS production leads to tissue/cell death and injury. ${ }^{10}$ Adenosine has been verified to participate in basal ROS generation within the epithelial cells. ${ }^{11}$ Nonetheless, it remains unclear whether adenosine triggers ROS generation in cancer cells. The study by Ma et al showed that adenosine increased the ROS level and induced mitochondrial dysfunction, thus causing apoptosis of the hepatocellular carcinoma (HCC) cells. ${ }^{12}$ Nevertheless, it remains unclear whether adenosine can induce apoptosis of ovarian cancer cells by increasing the ROS level. Therefore, this study aimed to examine the effects of Ado on the proliferation of ovarian cancer cell line A2780 as well as its related mechanism, which provided a theoretical basis for the development of Ado as a chemotherapeutic agent for ovarian cancer.

\section{Materials And Methods}

\section{Materials}

The human ovarian cancer cell lines A2780 and SKOV3 were purchased from the American Type Culture Collection (ATCC). Adenosine ( $>99 \%$ purity) was provided by SigmaAldrich (Cat NO: A9251, Milwaukee, WI). DMEM, fetal bovine serum (FBS) and trypsin were obtained from Gibco (Grand Island, NY, USA). MTT was derived from SigmaAldrich (Milwaukee, WI), and the Annexin V-FITC/7-AAD apoptosis detection kit was offered by BD Biosciences (San Jose, CA). The Hoechst 33342 staining kit, ROS kit, JC-1 kit, and BCA protein assay kit were provided by the Beyotime Institute of Biotechnology (Jiangsu, China). The antibodies against $\beta$-actin, caspase-3, cleaved caspase-3, Bax, Cytochrome C, $\beta$-Tubulin, VDAC and poly (ADPribose) polymerase (PARP) were derived from Cell Signaling Technology (Danvers, MA, USA).

\section{Inhibitory Effects Of Ado On A2780 And SKOV3 Cells Detected By MTT Assay}

Ovarian cancer A2780 and SKOV3 cells at the exponential phase were digested using trypsin, so as to produce the cell suspension of approximately $6 \times 10^{4}$ cells $/ \mathrm{mL}$. Cells were then inoculated into the 96 -well plates at a density of 100 $\mu \mathrm{L} /$ well. After being cultured in the $37^{\circ} \mathrm{C}$ incubator under $5 \% \mathrm{CO}_{2}$ condition until cell adherence, the medium was removed, and new mediums supplemented with different concentrations of Ado $(0,10,20,40$, and $80 \mathrm{mmol} / \mathrm{L})$ were added. After $24 \mathrm{~h}$ and $48 \mathrm{~h}$ of treatment, $20 \mu \mathrm{L}$ of $5 \mathrm{mg} / \mathrm{mL}$ MTT was added into the culture mediums to incubate for another $4 \mathrm{~h}$. Afterwards, the supernatant was removed, and $150 \mu \mathrm{L}$ dimethyl sulfoxide (DMSO) was added into each well and dissolved completely at $37^{\circ} \mathrm{C}$. Subsequently, the absorbance (A) value was assessed at the wavelength of 490 $\mathrm{nm}$. The cell inhibition rate (\%) was calculated according to the formula:

[1 - (the average A value of the treatment group)/ (the average A value of the control group)] $\times 100 \%$.

\section{Effect Of Adenosine On Morphological Changes And Apoptosis Rate Of A2780 And SKOV3 Cells By Hoechst 33342}

\section{Staining}

Cells were inoculated onto the 96-well plate as described in section 1.2. After achieving cell adherence, cells were treated with mediums supplemented with Ado at various concentrations $(0,10,20$, and $40 \mathrm{mmol} / \mathrm{L})$ for $24 \mathrm{~h}$, and examined using the Hoechst 33342 staining kit in accordance with the manufacturer protocols. The results were observed under the fluorescence microscope $(\times 200)$ at UV wavelength excitation. A total of 200 cells from randomly chosen six microscopic fields were counted, and the percentage of apoptotic cells in the total number of cells was calculated.

\section{Apoptosis Rate Of A2780 And SKOV3 Cells Assessed By Flow Cytometry}

A2780 and SKOV3 cells at the exponential phase were prepared into the $1 \times 10^{5}$ cells $/ \mathrm{mL}$ suspension and then inoculated into 6-well plates at a density of $1 \mathrm{~mL} / \mathrm{well}$. Thereafter, each plate was placed into the cell incubator until cell adherence, then the medium was discarded, and cells were treated with Ado at the concentrations of 0 (negative control), 10, 20, or $40 \mathrm{mmol} / \mathrm{L}$ for $24 \mathrm{~h}$. Cells 
were then digested with trypsin in the absence of EDTA and were harvested. Subsequently, cells were processed using the Annexin V-FITC/7-AAD apoptosis assessment kit following the manufacturer instructions. A scatter plot with the logarithmic axes was generated using the fluorescence of PE-Annexin-V (X-axis) and PI (Y-axis). In the four resultant quadrants, the right upper quadrant represented the damaged cells during collection, the left upper quadrant stood for the late apoptotic and necrotic cells, the left lower quadrant suggested the living cells, whereas the right lower quadrant suggested the early apoptotic cells. The proportion attributed to each quadrant represented the ratio of cell number in the quadrant to the total cell number examined. The experiment was performed in triplicate.

\section{ROS And MMP Detected By DCFH-DA And JC-I}

ROS and MMP were assessed according to the DCFH-DA and JC-1 methods, respectively. In brief, the treated A2780 and SKOV3 cells were collected by means of centrifugation and incubated with DCFH-DA for 30 min at room temperature. Then, the cells were washed with serum-free DMEM for three times, and the fluorescence intensity of ROS in each group was measured using flow cytometry within $30 \mathrm{~min}$. The excitation wavelength is $488 \mathrm{~nm}$ and the emission wavelength is $525 \mathrm{~nm}$. Rosup was used as a positive control. The negative control was wells with cells only.

Afterwards, A2780 and SKOV3 cells were incubated with $1 \mathrm{~mL}$ JC-1 staining solution for $20 \mathrm{~min}$ at $37{ }^{\circ} \mathrm{C}$, followed by washing twice with $1 \times$ staining buffer and addition into $1 \mathrm{~mL}$ DMEM. Later, the fluorescence intensity of MMP was measured through flow cytometry within $15 \mathrm{~min}$, and the results were expressed as the ratio of red fluorescence to green fluorescence. The excitation wavelength is $490 \mathrm{~nm}$ and the emission wavelength is $530 \mathrm{~nm}$. Carbonylcyanidemchlorophenylhydrazone (CCCP) was used as a positive control. The negative control was wells with cells only.

\section{Subcellular Fractionation}

The Mitochondria/cytosol Fractionation Kit (Beyotime, China) was adopted to isolate cytosolic protein from the mitochondrial protein in accordance with manufacturer protocol; then, cells were collected to resuspend within the hypotonic buffer at $4{ }^{\circ} \mathrm{C}$ for $10 \mathrm{~min}$. Cell fractionation, which included differential centrifugation and syringe homogenization, was carried out. To be specific, the unbroken cells as well as nuclei were removed through 4 min of centrifugation at $1000 \mathrm{~g}$ and $4^{\circ} \mathrm{C}$; afterwards, the portion of heavy membrane was subjected to $10 \mathrm{~min}$ of sedimentation at $11,000 \mathrm{~g}$. Later, the supernatant was collected, followed by another $10 \mathrm{~min}$ of centrifugation at $12,000 \mathrm{~g}$, so as to produce the portion of light membrane. Afterwards, the supernatants obtained from centrifugation at $12,000 \mathrm{~g}$ were collected, which was the cytosolic fraction. Thereafter, the resultant portion of the heavy membrane (mitochondrial), together with the cytosolic fraction, was carried out SDS-PAGE as well as Western blotting.

\section{Western Blotting Of The Apoptosis- Related Proteins And Mitochondrial Proteins}

A2780 and SKOV3 cells were treated with Ado at various concentrations. Subsequently, the medium was discarded and cells were washed twice with PBS. After the addition of an appropriate amount of lysis solution and incubation on ice for $30 \mathrm{~min}$, the adherent cells were scraped using a cell scraper, and the resultant lysis solution was collected into the $1.5 \mathrm{~mL}$ centrifuge tubes. After centrifugation at $12,000 \mathrm{rpm}$ for $15 \mathrm{~min}$ at $4^{\circ} \mathrm{C}$, the protein concentration in the supernatant was determined by the BCA method, followed by denaturation in the $98^{\circ} \mathrm{C}$ metal bath for $5 \mathrm{~min}$. Thirty-milligram protein samples were separated by means of $12 \%$ SDSPAGE, and then the proteins were transferred onto the PVDF membrane. Afterwards, the membrane was blocked with $5 \%$ skim milk for $1 \mathrm{~h}$, and incubated overnight or for $12 \mathrm{~h}$ at $4^{\circ} \mathrm{C}$ with the corresponding primary antibody. The primary antibodies were used at a dilution of 1:1000 (Caspase-3, Cleaved-Caspase-3, Cleaved-PARP, Cyto C) or 1:2000 (Bax,Bcl-2, PARP, $\beta$-actin,VDAC, $\beta$-Tubulin). Next, the membrane was washed with TBST for 5 min three times, incubated with secondary antibody at room temperature for $1 \mathrm{~h}$, and washed with TBST for $10 \mathrm{~min}$ three times. The target protein was then visualized by the chemiluminescence method, the membrane was photographed using the gel imager, and the gray value was analyzed via the Image-J software.

\section{Statistical Methods}

Quantitative data were expressed as $\bar{x} \pm s$. The Student's $t$-test was adopted for comparison between two groups, and Dunnett's Multiple Comparison Test was adopted for comparisons among multiple groups. All data were analyzed 
using the SPSS 19.0 software, and a difference of $P<0.05$ was considered as statistically significant.

\section{Results}

\section{Effects Of Adenosine On The} Proliferation Of Ovarian Cancer A2780

\section{And SKOV3 Cells}

MTT assay results showed that adenosine remarkably inhibited the proliferation of A2780 and SKOV3 cells. The inhibitory effect of adenosine on A2780 and SKOV3 cells increased gradually as the concentration and treatment time increased. Notably, the results suggested that the inhibition rate of A2780 and SKOV3 cells treated with $80 \mathrm{mmol} / \mathrm{L}$ Ado for $48 \mathrm{~h}$ was as high as $84.3 \%, 79.1 \%$, respectively. Data are displayed in Figure 1.

\section{Effects Of Adenosine On The} Morphological Changes And Apoptosis Rate Of Ovarian Cancer A2780 And SKOV3 Cells

Results of Hoechst 33342 staining revealed that apoptosis occurred in A2780 and SKOV3 cells following adenosine treatment. Uniform and weak fluorescence was observed in the control group; by contrast, the nuclei in the treatment group were visibly shrunk, and bright blue apoptotic bodies were observed. Notably, the bright blue apoptotic bodies began to appear when A2780 and SKOV3 cells were treated with $10 \mathrm{mmol} / \mathrm{L}$ adenosine for $24 \mathrm{~h}$, and the percentage of apoptotic cells increased remarkably at $40 \mathrm{mmol} / \mathrm{L}$. Data are presented in Figure 2A.

\section{Effects Of Adenosine On The Apoptosis Rate Of Ovarian Cancer A2780 And SKOV3 Cells}

Results of flow cytometry revealed that adenosine induced the apoptosis of A2780 and SKOV3 cells, and the apoptosis rate increased with the increase in adenosine concentration. At the adenosine concentration of $40 \mathrm{mmol} / \mathrm{L}$, the apoptosis rate was as high as $40.2 \%$. Data are displayed in Figure 2B.

\section{Effects Of Adenosine On The ROS Level In Ovarian Cancer A2780 And SKOV3 Cells}

Indirect fluorescence assay revealed that adenosine outstandingly increased the intracellular ROS level in A2780 and SKOV3 cells. Compared with the control group, $10 \mathrm{mmol} / \mathrm{L}$ adenosine treatment evidently elevated the ROS level $(P<0.01)$ in a dose-dependent manner. Data are presented in Figure 3A.

\section{Effects Of Adenosine On The MMP Of Ovarian Cancer A2780 And SKOV3 Cells}

Mitochondrial membrane potential change is one of the earliest events in apoptosis. We evaluated the effects of adenosine on MMP of A2780 and SKOV3 cells by JC-1 staining. As shown in Figure 3B, Ado notably decreased the MMP of A2780 and SKOV3 cells in a dose-dependent manner.
A2780

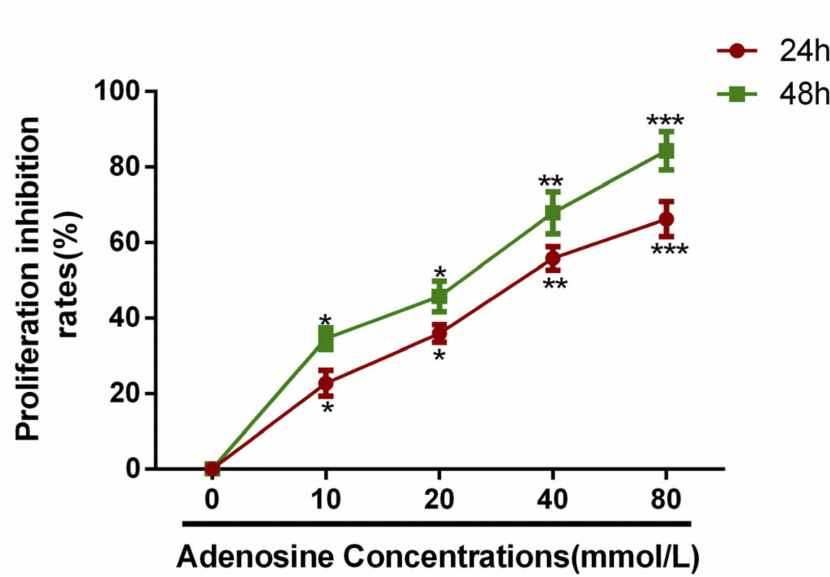

SKOV3

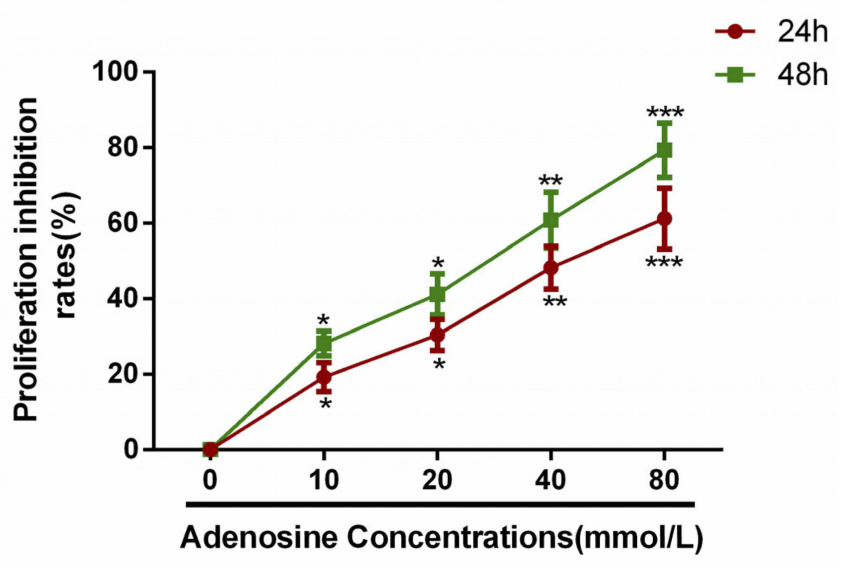

Figure I Adenosine inhibited the growth of ovarian cancer cells.

Notes: A2780 and SKOV3 cells were treated with Adenosine $(0 \mathrm{mM}, 10 \mathrm{mM}, 20 \mathrm{mM}, 40 \mathrm{nM}$ and $80 \mathrm{mM})$ for indicated periods (24 h, $48 \mathrm{~h})$ and then subjected to the MTT assay. $* P<0.05, * * P<0.01$, and $* * * P<0.001$ compared with control. 
A
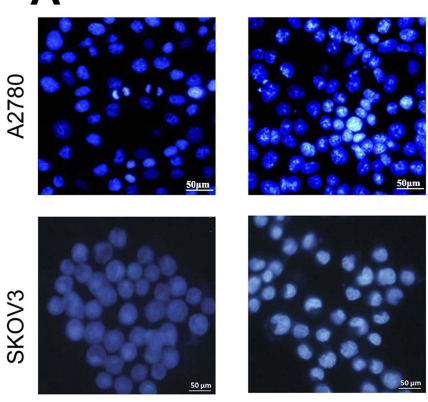
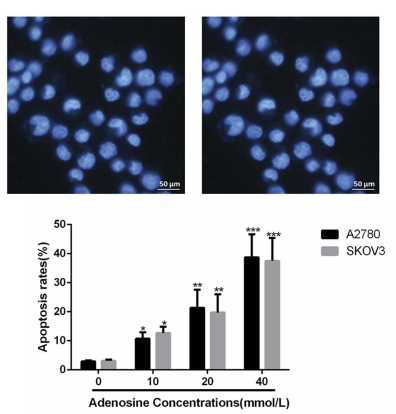

B
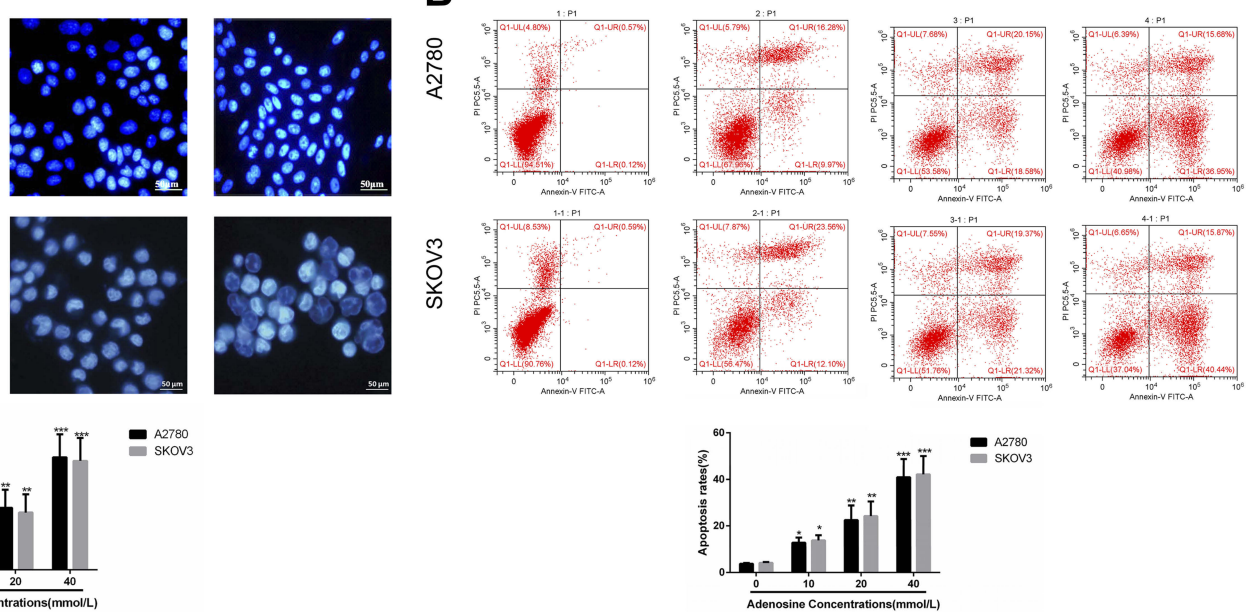

Figure 2 Adenosine-induced apoptosis in ovarian cancer cells.

Notes: A2780 and SKOV3 cells were treated with Adenosine $(0 \mathrm{mM}, 10 \mathrm{mM}, 20 \mathrm{mM}, 40 \mathrm{nM})$ for $24 \mathrm{~h}$. (A) Apoptosis was analyzed using Hoechst 33342 . (B) Apoptosis was analyzed using Annexin-V/PI. $* P<0.05, * * P<0.01$, and $* * P<0.001$ compared with control.

A
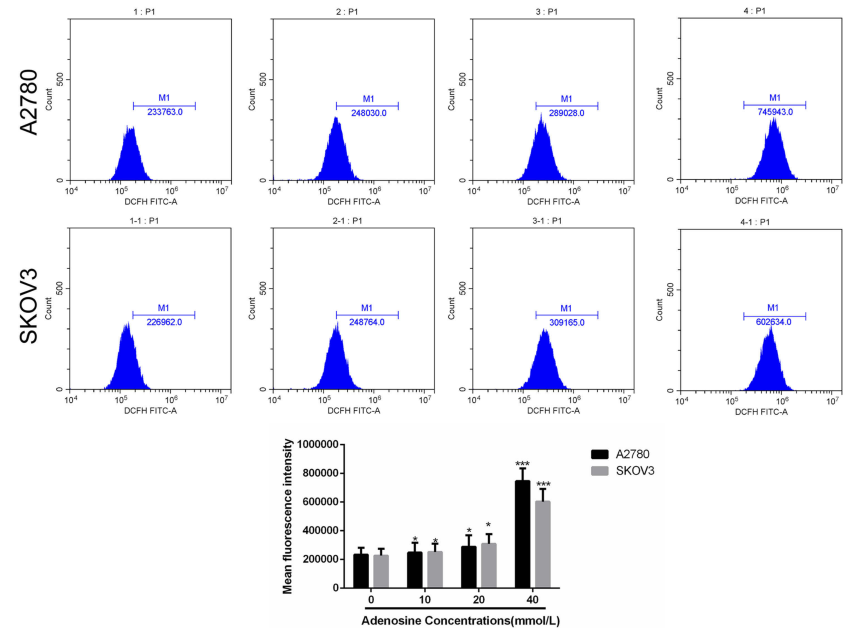

B
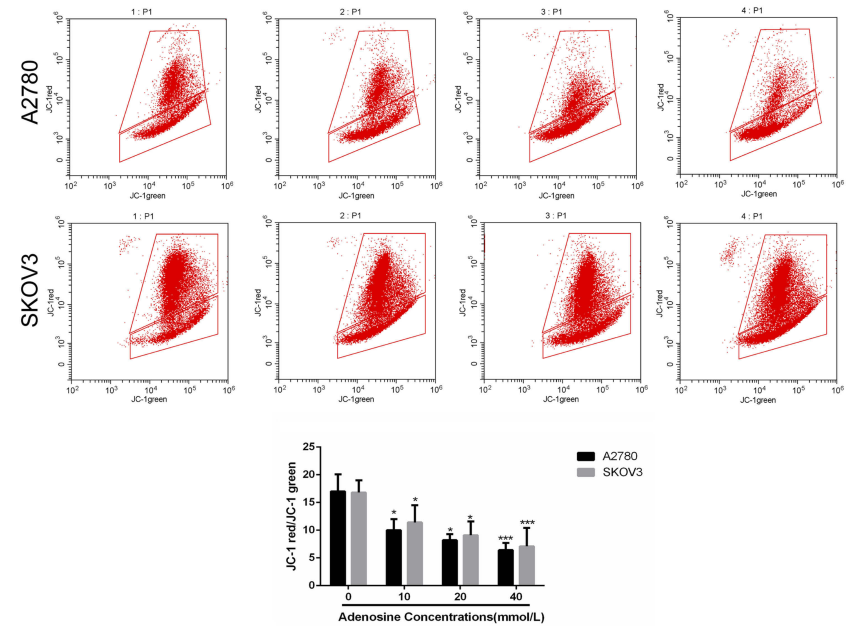

Figure 3 Effects of Adenosine on ROS level (A) and MMP (B) in A2780 and SKOV3 cells.

Notes: A2780 (A) and SKOV3 (B) cells were treated with Adenosine ( $0 \mathrm{mmol} / \mathrm{L}, 10 \mathrm{mmol} / \mathrm{L}, 20 \mathrm{mmol} / \mathrm{L}$, and $40 \mathrm{mmol} / \mathrm{L})$ for $24 \mathrm{~h}$. The reactive oxygen species (ROS) and mitochondrial membrane potential (MMP) were assessed according to the DCFH-DA and JC-I methods. $* P<0.05$, $* * P<0.0$ I, and $* * * P<0.00$ I compared with control.

\section{Effects Of Adenosine On The Apoptosis- Related Proteins In A2780 And SKOV3 Cells}

Western blotting revealed that after adenosine treatment for 24 $\mathrm{h}$ the expression of pro-apoptotic protein Bax in A2780 cells was up-regulated, and that of the apoptotic protein Bcl-2 was down-regulated. Besides, the ratio of the two groups increased with the increase in adenosine concentration. Cleaved-caspase-
3 and cleaved-PARP were also detected. Data are shown in Figure $4 \mathrm{~A}$ and $\mathrm{B}$.

\section{Effects Of Adenosine On Mitochondrial Proteins In A2780 And SKOV3 Cells}

The above results suggested that adenosine broke the mitochondrial membrane stability of ovarian cancer cells, resulted in a reduction in transmembrane potential, 
A

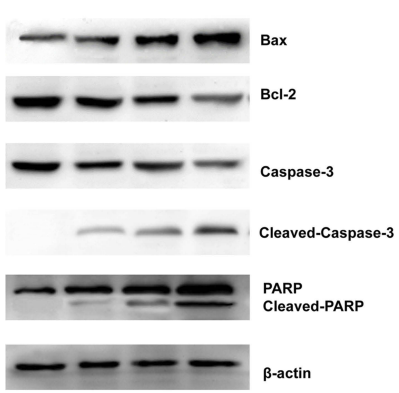

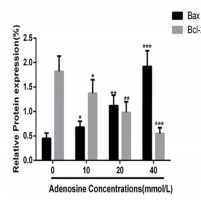

$\min _{\operatorname{moc} 2}$
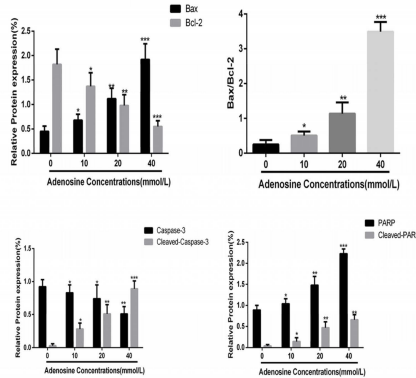

B

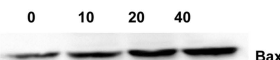

$-\infty-\mathrm{Bcl-2}$
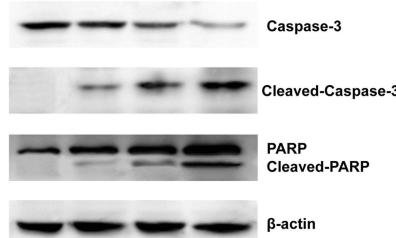

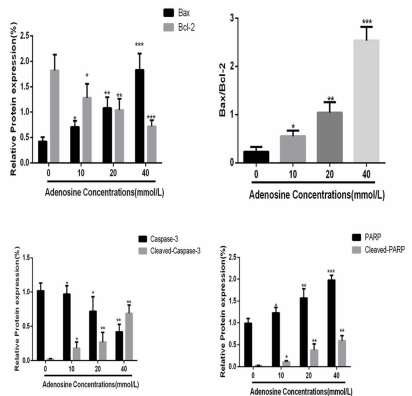

Figure 4 Effects of Adenosine on the expression of apoptosis-related proteins.

Notes: A2780 (A) and SKOV3 (B) cells were treated with Adenosine $(0 \mathrm{mmol} / \mathrm{L}, 10 \mathrm{mmol} / \mathrm{L}, 20 \mathrm{mmol} / \mathrm{L}$, and $40 \mathrm{mmol} / \mathrm{L})$ for $24 \mathrm{~h}$. The levels of total Bax, Bcl2, Bax/Bcl-2, Caspase-3, Cleaved-Caspase-3, PARP, Cleaved-PARP and $\beta$-actin were analyzed by Western blot. $* P<0.05$, $* * P<0.01$, and $* * * P<0.001$ compared with control.

and thereby promoted the apoptosis of A2780 and SKOV3 cells. After mitochondrial membrane rupture, multiple soluble proteins in intermembrane space were released into the cytoplasm, including CytoC, AIF and SMAC/DIABLO, which induced cell apoptosis through activating the Caspase pathway. The release of CytoC from mitochondria to cytoplasm was a key event of cell apoptosis.

To verify whether adenosine induced the release of mitochondrial intermembrane space protein into the cytoplasm, adenosine at the doses of $0,10,20$ and $40 \mathrm{mmol} / \mathrm{L}$ was used to treat A2780 and SKOV3 cells, respectively. Twenty-four hours later, cells were collected, the cytosolic protein was isolated from the mitochondrial protein, and the CytoC expression was detected using the Western blotting assay subsequently. As shown in Figure $5 \mathrm{~A}$ and $\mathrm{B}$, with the increase in drug concentration, the CytoC expression in mitochondria was gradually reduced, while that in the cytoplasm was gradually increased, suggesting that adenosine promoted the release of CytoC from mitochondria to the cytoplasm.

\section{Discussion}

Our study showed that adenosine induces apoptosis of A2780 and SKOV3 cells through leading to the mitochondrial membrane dysfunction by means of enhancing the intracellular ROS level, which also activates Caspase-3, increases Bax expression, and reduces Bcl-2 expression. The mitochondrial membrane dysfunction further causes the release of mitochondrial protein Cyto $\mathrm{C}$, eventually activating Caspase-3 and PARP. Consequently, it leads to ovarian cancer cell death.
A
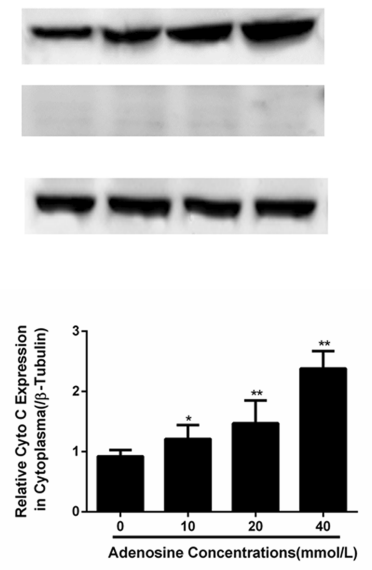
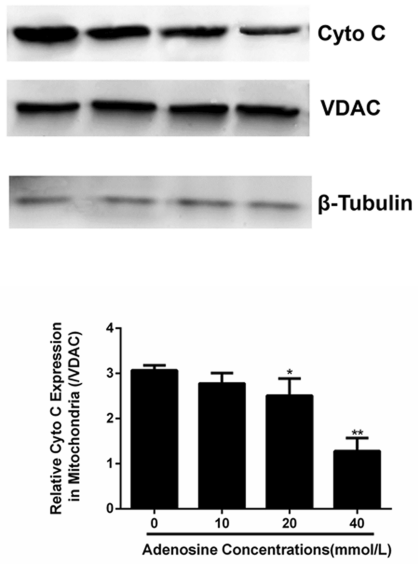

B
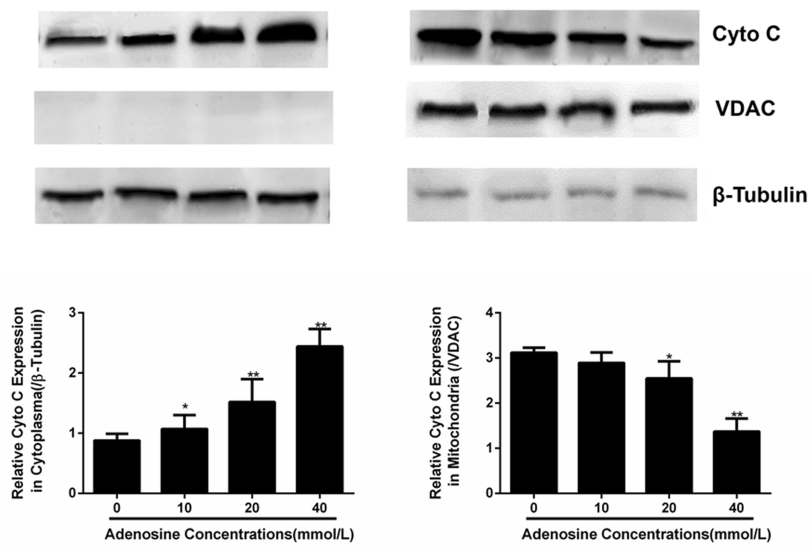

Figure 5 Effects of Adenosine on the expression of mitochondrial proteins.

Notes: A2780 (A) and SKOV3 (B) cells were treated with Adenosine $(0 \mathrm{mmol} / \mathrm{L}, 10 \mathrm{mmol} / \mathrm{L}, 20 \mathrm{mmol} / \mathrm{L}$, and $40 \mathrm{mmol} / \mathrm{L})$ for $24 \mathrm{~h}$. The levels of Cyto C in cytoplasm and mitochondria were analyzed by Western blot. $* P<0.05$, $* * P<0.01$, and $* * * P<0.001$ compared with control. 
The occurrence and development of ovarian cancer are related to multiple factors both in vitro and in vivo, among which, the uncontrolled cell proliferation and blocked apoptosis play vital roles. Under physiological conditions, adenosine acts through specific adenosine transporters or cell membrane receptors. ${ }^{13}$ Saito et al demonstrated that adenosine can induce apoptosis and inhibit the proliferation of colon cancer cell line CW2 through the A1 adenosine receptor. ${ }^{14}$ El-darahali et al found that adenosine induces the apoptosis of thymic cancer cell line EL-4 in a caspase-dependent manner through the nonclassical adenosine receptor pathway. ${ }^{15}$ Wen et al ${ }^{16}$ had investigated the effects of ATP and adenosine on the HCC cell line Li-7A and found that ATP inhibited cell proliferation in a dose- and time-dependent manner. The authors suggested that such inhibitory effect was achieved through the adenosine-induced cell apoptosis, while adenosine was produced during the degradation of ATP through activating the A3 adenosine receptor. They reported that adenosine induced cell apoptosis through at least two pathways, namely, the receptor pathway and the membrane transporter pathway. In this study, results of MTT assay suggested that $10 \mathrm{mmol} / \mathrm{L}$ adenosine treatment for $24 \mathrm{~h}$ markedly inhibited the proliferation of ovarian cancer A2780 and SKOV3 cells in a time- and dose-dependent manner. Morphologically, the cells developed nuclear pyknosis with the increase in Ado concentration, which showed a bright blue color. The cells were also recognizable by other apoptotic characteristics, including apoptotic bodies. Flow cytometry was carried out to accurately quantify the effect of adenosine on the apoptosis of ovarian cancer cells, which further proved that Ado induced the apoptosis of ovarian cancer cells in a dose-dependent manner. To understand the related mechanism, the ROS level in A2780 and SKOV3 cells treated with Ado was detected, and our results suggested that the ROS level increased rapidly, indicating that Ado broke the oxygen balance in ovarian cancer cells. Notably, ROS plays an important role in the normal proliferation and signal transduction of cells, which can induce cell apoptosis through DNA damage. ${ }^{17,18}$ This study suggested that Ado might induce apoptosis by inducing a large amount of ROS in A2780 and SKOV3 cells. Meanwhile, it was found that the MMP in the process of Ado-induced A2780 and SKOV3 apoptosis showed a characteristic continuous decline, which was consistent with the findings from a previous study. ${ }^{12}$

To explore the mechanism underlying the Adenosineinduced apoptosis, Western blotting was conducted to assess the expression levels of pro-apoptotic protein Bax and the apoptosis-related proteins caspase- 3 , cleaved-caspase-3, and PARP. Recent studies discover that proteins, including Bax and caspase-3, are involved in the endogenous apoptotic pathways. ${ }^{19}$ Bax is an important pro-apoptotic protein in the pro-apoptotic family, while Bcl-2 is an anti-apoptotic protein antagonized by Bax. The increase in the $\mathrm{Bax} / \mathrm{Bcl}-2$ ratio indicates that $\mathrm{Bax}$ is activated, which induces cell apoptosis. Caspase- 3 is an important protease in the caspase family, which is activated by the pro-apoptotic factors and plays a vital part as an executor in early apoptosis. $^{20}$ The activated caspase-3 can specifically degrade cell proteins and PARP, ${ }^{21}$ while PARP is an important DNA repair enzyme in eukaryotes, which repairs DNA damage and promotes tumor growth. ${ }^{22}$ Our results indicated that, in A2780 and SKOV3 cells treated with $20 \mathrm{mmol} / \mathrm{L}$ Ado, the expression of pro-apoptotic protein Bax was up-regulated, and caspase- 3 and PARP were fragmented, suggesting that Adenosine might induce cell apoptosis through enhancing the expression of proapoptotic protein Bax and activating caspase-3. According to previous studies, adenosine induces cell cycle arrest and apoptosis through the cyclinD1/Cdk4 and the Bcl-2/Bax pathways in human ovarian cancer cell line OVCAR-3. ${ }^{23}$

In conclusion, Adenosine can remarkably inhibit the proliferation of ovarian cancer cell lines A2780 and SKOV3 in a dose-dependent manner, which may also induce the apoptosis of A2780 and SKOV3 cells by increasing the ROS level, up-regulating the expression of proapoptotic protein Bax, and activating caspase-3. This study suggests that Adenosine has some antitumor activity, which displays a promising prospect for research and development. However, further research is needed to develop Adenosine into a clinically effective anticancer drug.

\section{Disclosure}

These authors report no conflicts of interest in this work.

\section{References}

1. Yang Q, Yang Y, Zhou N, et al. Epigenetics in ovarian cancer: premise, properties, and perspectives. Mol Cancer. 2018;17(1):109.

2. Zheng H, Liu JY, Song FJ, Chen KX. Advances in circulating microRNAs as diagnostic and prognostic markers for ovarian cancer. Cancer Biol Med. 2013;10(3):123-130.

3. Helleman J, Jansen MP, Burger C, van der Burg ME, Berns EM. Integrated genomics of chemotherapy resistant ovarian cancer: a role for extracellular matrix, TGFbeta and regulating microRNAs. Int $J$ Biochem Cell Biol. 2010;42(1):25-30.

4. Agarwal R, Kaye SB. Ovarian cancer: strategies for overcoming resistance to chemotherapy. Nat Rev Cancer. 2003;3(7):502-516.

5. Wang D, Yu C, Xu L, et al. Nucleoside analogue-based supramolecular nanodrugs driven by molecular recognition for synergistic cancer therapy. J Am Chem Soc. 2018;140(28):8797-8806.

6. Gessi S, Merighi S, Sacchetto V, Simioni C, Borea PA. Adenosine receptors and cancer. Biochim Biophys Acta. 2011;1808(5):1400-1412. 
7. Epperson SA, Brunton LL, Ramirez-Sanchez I, Villarreal F. Adenosine receptors and second messenger signaling pathways in rat cardiac fibroblasts. Am J Physiol Cell Physiol. 2009;296(5):C1171-7.

8. Kang J, Pervaiz S. Mitochondria: redox metabolism and dysfunction. Biochem Res Int. 2012;2012:896751.

9. Keeble JA, Gilmore AP. Apoptosis commitment-translating survival signals into decisions on mitochondria. Cell Res. 2007;17(12):976-984.

10. Yoboue ED, Devin A. Reactive oxygen species-mediated control of mitochondrial biogenesis. Int J Cell Biol. 2012;2012:403870.

11. Thakur S, Du J, Hourani S, Ledent C, Li JM. Inactivation of adenosine A2A receptor attenuates basal and angiotensin II-induced ROS production by Nox2 in endothelial cells. J Biol Chem. 2010;285 (51):40104-40113.

12. Ma Y, Zhang J, Zhang Q, et al. Adenosine induces apoptosis in human liver cancer cells through ROS production and mitochondrial dysfunction. Biochem Biophys Res Commun. 2014;448(1):8-14.

13. Sek K, Mølck C, Stewart GD, Kats L, Darcy PK, Beavis PA. Targeting adenosine receptor signaling in cancer immunotherapy. Int J Mol Sci. 2018;19:12.

14. Saito M, Yaguchi T, Yasuda Y, Nakano T, Nishizaki T. Adenosine suppresses CW2 human colonic cancer growth by inducing apoptosis via A(1) adenosine receptors. Cancer Lett. 2010;290 (2):211-215.

15. El-Darahali A, Fawcett H, Mader JS, Conrad DM, Hoskin DW. Adenosine-induced apoptosis in EL-4 thymoma cells is caspaseindependent and mediated through a non-classical adenosine receptor. Exp Mol Pathol. 2005;79(3):249-258.

16. Wen LT, Knowles AF, Extracellular AT. P and adenosine induce cell apoptosis of human hepatoma Li-7A cells via the A3 adenosine receptor. Br J Pharmacol. 2003;140(6):1009-1018.
17. Zhang L, Cheng X, Gao Y, et al. Induction of ROS-independent DNA damage by curcumin leads to G2/M cell cycle arrest and apoptosis in human papillary thyroid carcinoma BCPAP cells. Food Funct. 2016;7 (1):315-325.

18. Park C, Cha HJ, Hong SH, et al. Protective effect of phloroglucinol on oxidative stress-induced DNA damage and apoptosis through activation of the Nrf2/HO-1 signaling pathway in HaCaT human keratinocytes. Mar Drugs. 2019;17:4.

19. Tran N, Abhyankar V, Nguyen K, Weidanz J, Gao J. MicroRNA dysregulational synergistic network: discovering microRNA dysregulatory modules across subtypes in non-small cell lung cancers. $B M C$ Bioinformatics. 2018;19(Suppl 20):504.

20. Varghese J, Khandre NS, Sarin A. Caspase-3 activation is an early event and initiates apoptotic damage in a human leukemia cell line. Apoptosis. 2003;8(4):363-370.

21. Wesierska-Gadek J, Gueorguieva M, Wojciechowski J, TudzarovaTrajkovska S. In vivo activated caspase-3 cleaves PARP-1 in rat liver after administration of the hepatocarcinogen N-nitrosomorpholine (NNM) generating the $85 \mathrm{kDa}$ fragment. J Cell Biochem. 2004;93(4):774-787.

22. Zaremba T, Thomas H, Cole M, Plummer ER, Curtin NJ. Doxorubicininduced suppression of poly(ADP-ribose) polymerase-1 (PARP-1) activity and expression and its implication for PARP inhibitors in clinical trials. Cancer Chemother Pharmacol. 2010;66(4):807-812.

23. Shirali S, Aghaei M, Shabani M, Fathi M, Sohrabi M, Moeinifard M. Adenosine induces cell cycle arrest and apoptosis via cyclinD1/Cdk4 and Bcl-2/Bax pathways in human ovarian cancer cell line OVCAR3. Tumour Biol. 2013;34(2):1085-1095.

\section{Publish your work in this journal}

OncoTargets and Therapy is an international, peer-reviewed, open access journal focusing on the pathological basis of all cancers, potential targets for therapy and treatment protocols employed to improve the management of cancer patients. The journal also focuses on the impact of management programs and new therapeutic agents and protocols on patient perspectives such as quality of life, adherence and satisfaction. The manuscript management system is completely online and includes a very quick and fair peer-review system, which is all easy to use. Visit http://www.dovepress.com/ testimonials.php to read real quotes from published authors. 